\title{
Get Involved: Mengtao Xie, Student Advisory Council
}

\author{
Kelly Zappas
}

"Get Involved" is a recurring End Notes feature that spotlights the work of TMS volunteers and shows the wide range of activities available through TMS. This month, Mengtao Xie, a graduate student at Illinois Institute of Technology, discusses his work as a member and chair of the TMS Graduate Student Advisory Council.

Q. Could you describe what the TMS Graduate Student Advisory Council is and what it does?

A. The Graduate Student Advisory Council (GSAC) is the only student organization under TMS that aims specifically to address the professional needs of graduate students pursuing a career in materials science and engineering. We are working really hard to build the link between graduate students, materials professionals, and TMS. One project we have been doing is to provide valuable information on our Facebook page (GSAC TMS), including scholarship or internship opportunities and interview content with materials professionals.

Q. How did you become involved with the GSAC? Had you participated in any TMS activities before?

A. I received the International Symposium on Superalloys Scholarship at the Materials Science \& Technology 2010 (MS\&T'10) conference in Houston and was invited to the GSAC meeting. That is how the journey began. I had been involved in Material Advantage before.

Q. Is the council currently looking for new members? Who can participate and how can they get involved?

A. Definitely. We have many interesting activities going on, and we need your help to take us to the next level. Anybody can join our organization, as long as you are a TMS mem- ber. Just send us an email (gsac.tms@ gmail.com) or leave a comment on our Facebook page. We will include you in our next teleconference, and we can have face-to-face discussion with other members at the TMS and MS\&T conferences. By the way, we have uploaded all of the meeting minutes on our Facebook page just in case you want to know what is going on with us.

Q. As a member of the Graduate Student Advisory Council, what are your responsibilities? What can potential members expect to do if they get involved with the council?

A. The executive board does the strategic planning for our organization and breaks down those plans into pieces of detailed work. We expect our members to join our meetings and give us feedback about our plans. We need all of our members to help us with detail work, things like maintaining our Facebook page, interviewing people, editing our newsletter, and working with TMS on other projects.

Q. What is the time commitment involved in being a member of the council?

A. It would take about one or two hours per month for most of our members. The executive board will spend more time to operate our organization. We fully realize that we cannot let our activities affect our own study if we want to make our organization sustainable.
Q. Why would you encourage other graduate students to join the Graduate Student Advisory Council?

A. We have more materials graduate students than undergraduate students in the United States, yet we feel that the opportunities for graduate students are largely disproportional. We need to make our voice heard and make things better for graduate students. This will only happen if we, as graduate students, are willing to help ourselves. This would also be a great opportunity for graduate students to get involved with TMS, which is not quite as easy as for undergraduates. The GSAC is a relatively young organization. If you are really creative and enjoy making history, you should join us.

Q. Why do you volunteer with TMS? Have your volunteer experiences benefitted you as a graduate student?

A. I volunteer with TMS simply because I believe what I am doing with the GSAC now could potentially make things better for graduate students. My volunteer experiences have not only helped me with my resume, but also given me a great platform to network with materials professionals and other outstanding graduate students, who will become professionals one day. I also like the challenges involved in starting new things. These dots will be connected one day, I believe.

Kelly Zappas is a contributing writer for JOM. 